East African Medical Journal Vol. 86 No. 1 January 2009

MISDIAGNOSED ADULT TESTICULAR TORSION: CASE REPORT

P.L.W.Ndaguatha, MBChB, MMed (Surg), Senior Lecturer, Department of Surgery, College of Health Sciences, University of Nairobi, P.O. Box 19676-00202, Nairobi, Kenya

\title{
MISDIAGNOSED ADULT TESTICULAR TORSION: CASE REPORT
}

\author{
P. L. W. NDAGUATHA
}

\section{SUMMARY}

\begin{abstract}
Adult testicular torsion is thought to be rare if not relatively unusual. The rarity could be an underestimation since there are many episodes of missed torsions and misdiagnosis with other conditions of acute scrotum despite the now widespread ultra sound availability that are being reported in the literature. Such a misdiagnosis is herein reported of a 41 year old man.
\end{abstract}

\section{INTRODUCTION}

Scrotal pain is a common presenting symptom among patients referred to urosurgeons, and although the differential diagnosis may include benign aetiologies, one must not fall short of considering the other severe forms that are true urologic emergencies such as testicular torsion regardless of the age. Studies in the past have shown that this condition is not only most common in the adolescents but also in the adulthood $(1,2)$. It is well understood that acute testicular torsion in children must be diagnosed and urgently corrected if one was to avoid the loss of testis due to infarction. However, in the adults, the testicular torsion is rather rare as it is often unrecognised as the cause of scrotal pain. The diagnosis may be enhanced if careful anamnesis and physical examination of the patient along with colour doppler ultra sound are undertaken. However the current usage of the colour doppler ultrasonography although is said to assist in making the diagnosis in doubtful cases, its usage in gathering the clinical assessment and the information of patients with acute scrotal pain is operator dependent (3). It is therefore prudent to have the necessary clinical acumen in arriving at the diagnosis of the testicular torsion with or without the usage of colour doppler ultra sound. It is because of the above that the author has presented a case of a 41 year old man who had in the past beeninadvertently treated for repeated urinary tract infection because of the recurrent testicular pain and scrotal swellings. In the present episode, he similarly presented and despite the scrotal ultra sound being performed on him, the diagnosis was again said to be chronic epidydimo-orchitis in view of the ultra sound findings.

\section{CASE REPORT}

A 41 year old man arrived at the mater Hospital Accident and Emergency room (Casualty) at 9.30 am on $27^{\text {th }}$ February 2008 with two hour history of sudden severe right testicular pain. He had initially reported to another hospital on the same morning but was not comfortable with the treatment offered, hence his coming to the above hospital. At Casualty, he did say that he had a sudden onset of pain located to the right testicle that was later followed by the swelling. There was no aggravating factors (dysuria or urethral discharge) but was accompanied by nausea and vomiting that persisted till the time that was being reviewed. On further questioning, he did narrate of having had similar episodes in 1999 and 2006 though of shorter durations unlike the present episode that was unrelenting. In these two past episodes, he said that was treated for infection with antibiotics and pain killers and seemed to have faired relatively well. The physical examination during this current episode, other than general discomfort and mildly tender supra pubic region, he was found to have very tender swollen right testis. The examining doctor formed an impression of epididymo-orchits but ruled out testicular torsion, hence made arrangements for ultra-sound and laboratory investigations. The ultrasound report was availed later with the following comments:-

(i) Right testis is enlarged measuring $2.49 \times 3.22$ $\mathrm{cm}$.

(ii) Left testis measures $2.50 \times 2.37 \mathrm{~cm}$.

(iii) Both testis are of normal texture.

(iv) Rightepididymis is thickened and fluid is present around the testis.

(v) Epididymal body is also thickened.

(vi) The vascularity is present but reduced.

The conclusion by the radiologist was said to be in keeping with features of chronic epididymoorchitis.

In view of the above findings the author was informed via the phone of need to admit the patient with the above findings and the diagnosis. From the history given, the author advised the admitting doctor 
to admit the patient but to consider the possibility of testicular torsion despite the age and ultra-sound report. Review later in the ward, the patient repeated the same history to the author who noted that the right hemi scrotum was swollen. The testis was apparently seen lying at the neck of the scrotum and was very tender while the left one was seen to be lying transversely in the hemi-scrotum. With these findings, testicular torsion was thought to be most likely. The patient was then appraised of the possible pathology and advised about the need of undergoing testicular exploration. Urgent arrangement for the theatre was made for the above surgery after an informed consent was granted. Theatre was availed within eight hours of starting of the pain and at the testicular exploration, opening up the congested tunica vaginalis, an intra vaginal torsion of the right testis was evidently congested and somewhat dusky due to possible impending ischaemic gangrene as a result of the twisting of the cord by more than one turn, that is more than 180 degrees (Figure 1). With the first turn of derotation, the colour was seen to be changing from being dusky to pale pink (Figure 2) and after the complete derotation, the colouration of the testicle was seen to be promising; hence the need to wrap the testis and epididymis with warm packs for about 30 minutes, whilst exploring the contra-lateral testicle. It was found to be normal other than having a transverse lie as well as being within a deformed tunica vaginalis. After about 30 minutes, the deroted testis was re-examined and found to have recovered relatively well to the acceptable colour (Figure 3). Its viability was tested by nicking the testicular tunica albuginea with the $21 \mathrm{Fg}$ needle and was seen to have brisk pinkish red bleeding. A decision was therefore made to fix it to the dartos layer followed by the contralateral normal testis after Jaboulay hydrocelectomy.

Figure 1

View on opening up the tunica vaginalis; note the dusky nature of the testicle

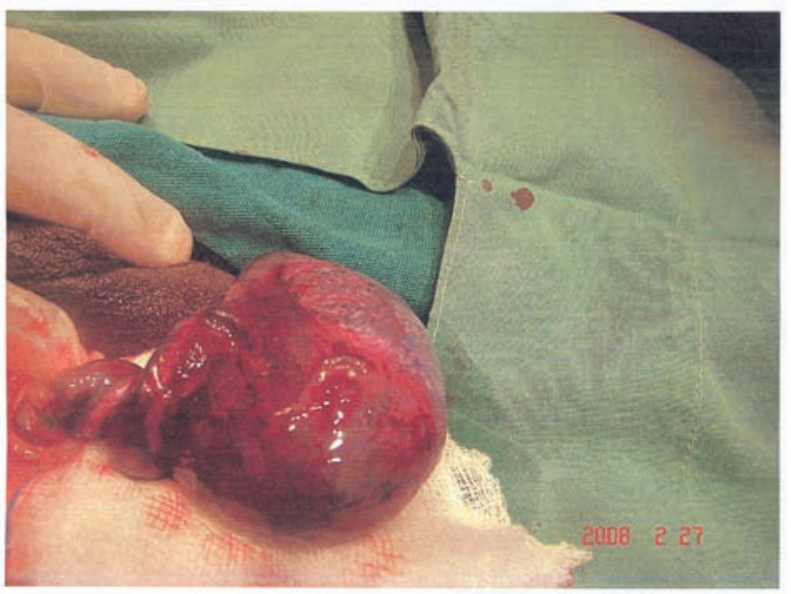

Figure 2

Beginning of detorsion. Note the colour improving to pink

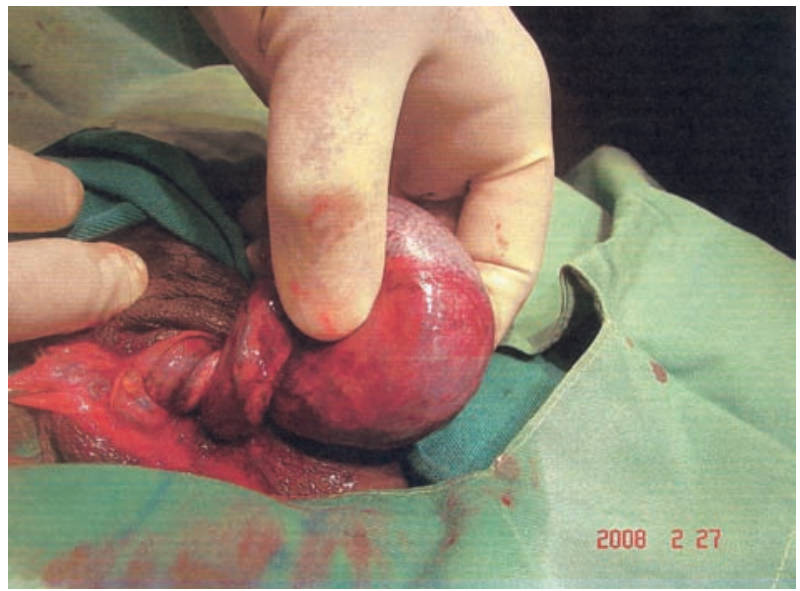

Figure 3

Twenty five minutes post detorsion. Relatively acceptable colour

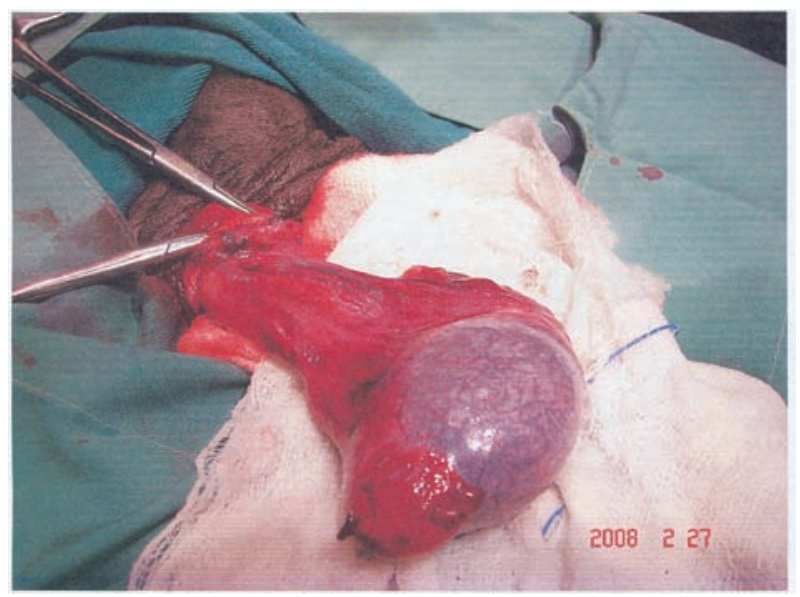

The post operative period was an uneventful and was therefore discharged and advised to have a fortnightly follow up as an out patient in order to detect any untoward effects if any. Two months later, the wounds were found to have healed fairly well. In order to ascertain the integrity of previously affected testis, the repeat ultra-sound was done after three months and the results were reported as: - Scrotal ultrasonography.

(i) Both testicles are normal in size and texture.

(ii) The right measures $3.69 \times 1.75 \times 2.33 \mathrm{~cm}$, the left $3.77 \times 2.35 \times 2.37 \mathrm{~cm}$.

(iii) No focal parenchymal lesion. Normal vascularity is seen on CFI.

He was last reviewed in July $11^{\text {th }} 2008$ in the consultant clinic and found to have faired well. He was therefore discharged from the urology clinic and advised to seek medical advice, should there be any problem there after. The last time he resurfaced was when he came along with his spouse to offer their compliments for not having lost his testis. 


\section{DISCUSSION}

Testicular torsion is a surgical emergency, both because it is a very painful condition and more importantly because delay means a permanent reduction or loss of fertility because of testicular infarction. The delayed diagnosis means loss of the affected testis possibly due to the misconception that the diagnosis is unlikely in the adults. This myth was discounted by Cummings et al (4) who showed in their study that torsion in adults was more common in their series than expected. They also showed that the salvage of the affected testis was better in younger patients, presumably due to less twisting of the cord (4). In view of the above it is likely that perhaps the adults surreptitiously loose their testis due to infarction as evidenced in some young couples who are continuously seeking for help because of infertility. It is therefore generally agreed that any male suspected of having testicular torsion requires immediate surgical exploration and fixation if the problem is to be avoided (5). It has been stated by some authors that there is a window period of approximately four to eight hours from onset of torsion symptoms until surgical intervention is required to save the testis (6). The patient being reported herein was surgically treated within this period and perhaps, though theinitial intra-operative findings were questionable, the consequent colour changes did justify the fixation. The above has to be born in mind so that there is no delay that might lead to orchidectomy and reduced fertility as a result of unilateral testicular loss (7). In order to obviate the above, good anamnesis and physical examination are very vital but if in any doubt of diagnosis, the usage of the colour doppler ultra-sound in good hands has showed to have a sensitivity of $89 \%$ and specificity of $100 \%(3,8)$ although in some cases the outcome is never the less, noted to be user dependant and according to the experience as is well exemplified in this case report.

Where the colour doppler sonography is done and supported by the history and physical examination, one should suspect torsion if there is intra-testicular absent or diminished flow (9). This scenario is well exemplified in this case being reported as the diagnosis was said to be chronic epididymo-orchitis although there was an indication of present but reduced vascularity. This report may have probably been otherwise, if the referring clinician had provided adequate clinical data to the radiology team doing the scans; as this would have alerted him or her to consider the possibility of torsion. It is important to note that this patient had in the past presented with two episodes of testicular pains and swellings without dysuria or urethral discharge but treated for the infection. Perhaps at that time the criteria for considering the infection was due to the mistaken belief that torsion was unlikely in that age. The present case being reported hence behoves one to consider the possibility of testicular torsion as the differential diagnosis in any male presenting with acute scrotum irrespective of the age (1). This patient may have been lucky in the past in not having the complete torsion in the past scenarios in 1999 and 2006 unlike the current episode where-in the diagnosis of chronic epididymo-orchitis would have continued with perhaps the disastrous effects if the history had not been considered by the author. A plea is therefore made to consider testicular torsion in adults with acute scrotal pain early enough in clinical evaluation so that testicular exploration is considered whether colour doppler ultra sound is available or not if all of the classic clinical criteria of epididymo orchitis are absent (10). The decision to fix the torted testis was based on the premise that orchidectomy should not be undertaken unless the parenchyma is clearly necrotic and that previous studies on salvageability of testis in torsion may be dictated by the testicular tissue bleeding (11). Such clinical findings of the colour improvement after application of warm packs and the presence of briskly pinkish red bleeding on nicking deeply into the parenchyma led to the above procedure being undertaken but keeping in mind that the salvaged testes should be assessed during the follow up. That this is possible was evident in this patient who was assessed three months later sonographically and found to have normal testicular texture and size as well as vascularity.

It is important to note that occasionally the patients may present with acute testicular pain despite having previously undergone testicular fixation. This may present the clinician with the diagnostic dilemma where promptaction is required. Therefore, for the good outcome of the scrotal procedures, the fixation must be such that one should aim at avoiding recurrent testicular torsion and possibility of increasing the risk of infertility and / or malignancy (12) as a result of wrong choice of sutures. Such reports have appeared in the literature and therefore prompted the incorporation of suture less fixations, in the form of dartos pouch orchidopexy $(6,13)$. After much debate on the evolution for post testicular torsion, it said that, if the testis is to be preserved, it should be placed into the dartos pouch without suture fixation and if suture fixation is elected, then fine non-reactive, non-asorbable sutures should be used, and they be placed so as to avoid superficial blood vessels on the surface of the testis. However, other reports in the literature do point out that the most important factor for the adhesion formation would appear to be the eversion of the tunica vaginalis as in the Jaboulay hydrocele repair along with the fixation of tunica albuginea to the dartos as in the case being reported (14). 


\section{ACKNOWLEDGEMENTS}

To the Mater Hospital for allowing me to publish this case report.

\section{REFERENCES}

1. Dennis, M.J.S., Fahim, S. F. and Doyle P.T. Testicular torsion in older men. Lesson of week. Brit. Med. J. 1997; 294: 1680

2. Patrick, D. and Jennifer, S. Testicular torsion in a 68 year old Man. Case Report. Urol. 2005; 66: 195e.31195e.32.

3. Pepe, P., Panella, P., et al. Does colour Doppler sonography improve the clinical assessment of patients with acute scrotum? Eur. J. Radiol., 2006; 60: 120-124.

4. Cummings J. M., Boullier, J. A., et al. Adult testicular torsion. J. Urol. 2002; 167: 2109-2110.

5. Osegbe, D. N. and Amaku, E.O. Torsion of testis in Nigerians. Afr. J. Med. Sci. 1981; 10: 97.

6. Shneck, F. X. and Bellinger, M. F. Abnormalities of the testes and scrotum and their surgical management. In: Campbell's Urology, 8th ed. Edited by PC Walsh, AB Retick, ED Vaughan, Jr and AJ Wein. Philadelphia: WB Saunders Co. Vo1.3, Sect. IX Chapt. 2002; 67: 23532394.
7. Schutte, B., Becker, H., et al. Exocrine and endocrine testicular function following unilateral torsion: a retrospective clinical study of 36 patients [in Germany]. Urologe A. 1986; 145-146.

8. Allan, T. and Elder J. Shortcoming of colour Doppler sonography in the diagnosis of testicular torsion. J. Urol. 1993; 154: 1508.

9. Lazarov, R., Stapper, G. et al. Testicular torsion can also occur in adult men. Ned. Tijdschr Geneeskd. 2003; 147: 1389-1939.

10. Tulia, B. M. and Newman, H. R. Testicular torsion in adults: plea for its consideration early in clinical evaluation of acute scrotum. Urol. Aug. 1997; 10: 150151.

11. Arda, I. S. and Ozyaylali, I. Testicular tissue bleeding as an indicator of gonadal salvageability in testicular torsion. Bru. Intern. 2001; 87: 89-92.

12. Gesino, A. and Bachmann DeSantos, M. E. Spermatic cord torsion after testicular Fixation. A different surgical approach and a revision of current techniques. Eur. J. Paediatr. Surg. 2001; 11: 404.

13. Frank, J. D. and O'Brien, M., Fixation of the testis. Bru. Int. 2002; 89: 331.

14. Henry, S. Kim, L. M., et al. Recurrent torsion after previous fixation. Review article. Annals of New Zealand J. Surg. 2002; 72: 46-48. 